\title{
The hypocholesterolaemic effects of sitostanol in the guinea pig are in part related to changes in hepatic lipids and lipoprotein composition
}

\author{
Tripurasundari Ramjiganesh ${ }^{1}$, Suheeta Roy ${ }^{1}$, Jonathan C. McIntyre ${ }^{2}$ and Maria Luz Fernandez ${ }^{1}$ \\ ${ }^{1}$ Department of Nutritional Sciences, University of Connecticut, Storrs, CT, USA \\ ${ }^{2}$ Monsanto Company, St. Louis, MO, 63167, USA
}

(Received 29 February 2000 - Revised 29 August 2000 - Accepted 21 September 2000)

\begin{abstract}
To evaluate some of the mechanisms involved in the plasma cholesterol lowering of sitostanol (SI), male Hartley guinea pigs were fed diets containing cholesterol $(0.25 \mathrm{~g} / 100 \mathrm{~g})$ and four doses of SI: either 0 (control), $0.75,1.5$ or $2.25 \mathrm{~g} / 100 \mathrm{~g}$. In addition a negative control $(-\mathrm{C})$ group with dietary cholesterol $(0.04 \mathrm{~g} / 100 \mathrm{~g})$ was included. Corn oil was used as the source of fat and the contribution of fat energy was $35 \%$. Plasma total cholesterol was 43, 49 and $53 \%$ $(P<0.0001)$ lower after SI intake compared to the control. Plasma LDL concentrations were 47, 53 and $61 \%$ lower with increasing doses of SI. In addition, intake of SI resulted in 26-42\% lower hepatic total cholesterol. Hepatic esterified cholesterol and triacylglycerols were 32 $60 \%$ and 55-61\% lower after SI intake. SI intake resulted in favourable plasma and hepatic cholesterol concentrations similar to those in guinea pigs fed low levels of dietary cholesterol $(-\mathrm{C})$. The LDL obtained from the control group had a higher number of molecules of free and esterified cholesterol than the SI groups. SI intake resulted in 69-71\% higher cholesterol excretion compared to the control. SI treatment enhanced the total faecal neutral sterol excretion by $54-58 \%$ compared to control and by $70-76 \%$ compared to the $(-\mathrm{C})$ group. These results suggest that SI might have its hypocholesterolaemic effect by reducing cholesterol absorption, which results in lower concentration of cholesterol in liver. This reduction in hepatic cholesterol might possibly alter hepatic cholesterol metabolism and affect lipoprotein concentration and composition.
\end{abstract}

Sitostanol: Hepatic lipids: Neutral sterols: Guinea pigs

Elevated levels of plasma cholesterol, particularly apolipoprotein B (apo-B)-containing lipoproteins are well documented as risk factors for cardiovascular disease (Stamler et al. 1986; McNamara, 1992). Phytosterols, or plant sterols, occur naturally in the non-saponifiable material of plant origin. $\beta$-Sitosterol is the most abundant plant sterol. Campesterol, stigmasterol, and dihydrobrassicasterol are found at a much lower concentration and sitostanol (SI) is found in almost negligible amounts in plants (Weihrauch \& Gardner, 1978).

Phytosterols have been shown to reduce plasma cholesterol concentrations in numerous animal (Sugano et al. 1976, 1977) and human studies (Lees et al. 1977; Becker et al. 1993; Pelletier et al. 1995). For example, oryzanol, a non-saponifiable plant sterol found in rice bran oil decreases cholesterol absorption and aortic fatty streak in hamsters (Rong et al. 1997) while tall oil, which contains $20 \%$ (w/w) sitostanol, lowers plasma cholesterol in both male and female hamsters (Ntanios et al. 1998). Benecol and soyabean, which contain plant sterols, lower plasma total and LDL cholesterol in humans (Weststrate \& Meijer, 1998). In addition, pure dietary sitostanol has also been shown to decrease plasma total and apo B cholesterol concentrations in golden Syrian hamsters (Ntanios \& Jones, 1998). Interestingly, a gender effect has also been observed. Soyabean-derived phytosterols have been shown to lower plasma cholesterol concentrations more effectively in female hamsters (Ntanios et al. 1998). Rapeseed oil margarines, containing stanol esters have been shown to lower plasma total and LDL cholesterol concentrations in humans by inhibiting cholesterol absorption. In addition, a synergistic effect has been observed when stanol esters were combined with statins (Vuorio et al. 2000). Furthermore, stanol ester margarines have been included as a dietary treatment for hyperlipidaemia, according to the Finnish guidelines (Vuorio et al. 2000).

\footnotetext{
Abbreviations: ( $-\mathrm{C})$, negative control; LDL-C, low density lipoprotein cholesterol; VLDL-C, very low-density lipoprotein cholesterol; TAG, triacylglycerol; SI, sitostanol.

* Corresponding author: Dr T. Ramjiganesh, fax +1 860486 3674, email TRR98001@uconnvm.uconn.edu
} 
SI, the saturated form of phyosterols, is not present in a typical American diet (Weihrauch \& Gardner, 1978). However, studies have shown that SI exerts a more powerful hypocholesterolaemic effect than the other phytosterols (Sugano et al. 1976, 1977; Lees et al. 1977; Becker et al. 1993). In spite of numerous published data (Lees et al. 1977; Becker et al. 1993; Pelletier et al. 1995), there are some aspects of cholesterol and lipoprotein metabolism, which have not been fully elucidated.

Several mechanisms are proposed to account for the action of phytosterols on lipid metabolism. These include competitive blocking of cholesterol absorption (Heinemann et al. 1988, 1993), increasing bile salt excretion (Salen et al. 1970), hindering cholesterol esterification (Ikeda \& Sugango, 1983), and displacement of cholesterol from bile salt micelles (Child \& Kuksis, 1986). Numerous studies have documented that phytosterols inhibit cholesterol absorption (Heinemann et al. 1988; Salen et al. 1970; Ikeda \& Sugano, 1983; Child \& Kuksis, 1986). The primary mechanism of action of phytosterols is a decrease in cholesterol absorption in the intestine. This probably suggests that important secondary mechanisms are taking place in the liver, as the liver is a major regulator of hepatic cholesterol homeostasis.

These studies were undertaken to evaluate the effects of SI on hepatic lipids and lipoprotein concentration and composition in the guinea pig. We have demonstrated that diet-induced changes in the composition of VLDL and LDL have important metabolic implications, which can explain in part, changes in plasma cholesterol concentrations (Fernandez et al. 1993, 1999).

Guinea pigs were chosen as the animal model because they transport the majority of cholesterol in the LDL fraction similar to humans (Lin et al. 1994). In addition, guinea pigs have a hepatic cholesterol pool consisting of more free than esterified cholesterol; the liver contributes to less than $20 \%$ for total cholesterol synthesis, and they have similar responses to dietary interventions (Fernandez \& McNamara, 1994).

\section{Materials and methods}

\section{Materials}

Reagents were obtained from the following sources. Enzymatic cholesterol and triacylglycerol (TAG) kits, cholesterol oxidase, cholesterol esterase and peroxidase were purchased from Boehringer-Mannheim (Indianapolis, IN, USA). Phospholipid and free cholesterol enzymatic kits were obtained from Wako Pure Chemical (Osaka, Japan). Quick-seal ultracentrifuge tubes were from Beckman (Palo Alto, CA, USA) and halothane from Halocarbon (Hackensack, NJ, USA). 5- $\alpha$ cholestane was obtained from Steraloids (Wilton, NH, USA) and petroleum ether and methylene chloride were obtained from Sigma chemicals (St. Louis, MO, USA). SI was provided by Monsanto Company (St. Louis, MO, USA).

\section{Diets}

Diets were prepared and pelleted by Research Diets Inc.
Table 1. Composition of experimental diets

(Values are $\mathrm{g} / 100 \mathrm{~g}$ for nutrients and $\mathrm{g} / 4185 \mathrm{~kJ}$ for nutrient caloric density for dietary groups $\mathrm{I}-\mathrm{V}$ )

\begin{tabular}{|c|c|c|c|c|c|}
\hline & 1 & II & III & IV & V \\
\hline \multicolumn{6}{|l|}{ Nutrient } \\
\hline Protein* & $22 \cdot 3$ & $22 \cdot 3$ & $22 \cdot 3$ & $22 \cdot 3$ & $22 \cdot 3$ \\
\hline Corn oil & 15 & 15 & 14.25 & 13.5 & $12 \cdot 75$ \\
\hline Sitostanol† & 0 & 0 & 0.75 & 1.5 & $2 \cdot 25$ \\
\hline Starch & 30 & 30 & 30 & 30 & 30 \\
\hline Sucrose & $10 \cdot 6$ & $10 \cdot 6$ & $10 \cdot 6$ & $10 \cdot 6$ & $10 \cdot 6$ \\
\hline Vitamins $\ddagger$ & 1.1 & $1 \cdot 1$ & 1.1 & 1.1 & 1.1 \\
\hline Minerals $\ddagger$ & $8 \cdot 2$ & $8 \cdot 2$ & $8 \cdot 2$ & $8 \cdot 2$ & $8 \cdot 2$ \\
\hline Fibre§ & $12 \cdot 5$ & $12 \cdot 5$ & 12.5 & 12.5 & $12 \cdot 5$ \\
\hline $\mathrm{Kcal} / \mathrm{g}$ & 3.87 & 3.87 & $3 \cdot 80$ & 3.73 & 3.66 \\
\hline \multicolumn{6}{|c|}{ Nutrient caloric density } \\
\hline Fibre & 32.2 & $32 \cdot 2$ & $32 \cdot 9$ & 33.5 & 34.2 \\
\hline Minerals & $21 \cdot 1$ & $22 \cdot 1$ & $21 \cdot 1$ & $21 \cdot 6$ & 21.9 \\
\hline Vitamins & 2.83 & 2.83 & 2.83 & 2.83 & $2 \cdot 8$ \\
\hline Protein & 57.4 & $60 \cdot 9$ & $58 \cdot 7$ & 59.8 & 57.4 \\
\hline Cholesterol & 0.64 & 0.10 & 0.66 & 0.67 & $0.6 \varsigma$ \\
\hline
\end{tabular}

Diet I is the negative control, Diet II is the control diet with $0 \% \mathrm{SI}$ and Diets II, IV and $\mathrm{V}$ have increasing concentrations of SI.

* Soyabean protein.

† SI is obtained from soyabean.

¥ Minerals and vitamins meet NRC requirement for guinea pigs.

$\S$ Fibre is made of a mixture of $10 \mathrm{~g} / 100 \mathrm{~g}$ cellulose and $2.5 \mathrm{~g} / 100 \mathrm{~g}$ guar gum.

(New Brunswick, NJ, USA). A formulation of the five diets is presented in Table 1. All the diets were identical in composition except for the amount of fat and the inclusion of SI. Diet I was the control diet and had $15 \%$ regular corn oil and $0.25 \%$ cholesterol. Diet II was a low cholesterol diet $(0.04 \%)$, the cholesterol equivalent to $300 \mathrm{mg} / \mathrm{d}$ in the human situation (Lin et al. 1994) and was used as a negative control ( $-\mathrm{C}$ ). Diets III, IV and V contained 0.75 , 1.5 or $2.25 \mathrm{~g} / 100 \mathrm{~g}$ of SI. The diets containing SI had slightly less caloric density than the control diets.

\section{Animals}

Fifty Male Hartley guinea pigs (Haran Sprague-Dawley, Indianapolis, IN, USA), weighing between 300 and $400 \mathrm{~g}$ were randomly assigned to one of the five dietary groups (ten per group). Four groups received SI 0, 0.75, 1.5 and $2.5 \mathrm{~g} / 100 \mathrm{~g}$. The fifth group (negative control) was added to compare the plasma cholesterol lowering of SI treated animals to guinea pigs fed a low cholesterol diet. Two guinea pigs were kept per metal cage and were housed in a light cycle room (light from 07.00 to 19.00) with a temperature of $23^{\circ} \mathrm{C}$ for a period of 4 weeks. The animals had free access to diet and water. Animals were killed by cardiac puncture after halothane anaesthesia and blood was collected to analyse plasma lipids and to isolate lipoproteins for further characterization. Liver was harvested to determine hepatic lipids. To measure the faecal neutral sterols six animals from each group were housed individually for $3 \mathrm{~d}$ and food intake was monitored and faeces were collected. Guinea pigs were randomly allocated to five groups. All these animal studies were conducted in accordance with US Public Health Service guidelines. The University of Connecticut Institutional Care and Use Committee approved the experimental protocols. 


\section{Lipoprotein isolation}

Plasma samples were obtained from blood collected by cardiac puncture from guinea pigs under halothane anaesthesia, with EDTA $(1.5 \mathrm{mg} / \mathrm{ml})$ as an anticoagulant. Plasma from each sample $(500 \mu \mathrm{l})$ was stored at $4^{\circ} \mathrm{C}$ for further analysis and the rest was used for lipoprotein isolation. A mixture of aprotonin $(0.5 \mathrm{ml} / 100 \mathrm{ml})$, phenylmethylsulfonyl fluoride (PMSF, $0.1 \mathrm{ml} / 100 \mathrm{ml}$ ), and sodium azide $(0.1 \mathrm{ml} / 100 \mathrm{ml})$ were added to the samples to prevent changes in lipoprotein concentration during isolation.

Lipoprotein isolation was done by sequential ultracentrifugation (Redgrave et al. 1975) in a LE-8M Ultracentrifuge (Beckman Instruments, Palo Alto, CA, USA). VLDL was isolated at a density of $1.006 \mathrm{~g} / \mathrm{ml}$ at $125000 \mathrm{~g}$ at $15^{\circ} \mathrm{C}$ for $19 \mathrm{~h}$ in a Ti-50 rotor. LDL was isolated in a density range of $1.019-1.09 \mathrm{~g} / \mathrm{ml}$ in quick-seal tubes at $15^{\circ} \mathrm{C}$ for $3 \mathrm{~h}$ at $200000 \mathrm{~g}$ in a vertical Ti-65.2 rotor (Fernandez et al. 1999).

\section{Plasma and hepatic lipids}

Plasma samples were analysed for cholesterol and TAG by enzymatic methods (Allain et al. 1974). Plasma HDL cholesterol was determined by precipitating the apo-Bcontaining lipoproteins (Warnick et al. 1992) with a modification consisting of the use of $2 \mathrm{M} \mathrm{MgCl}_{2}$ (Fernandez et al. 1999). Hepatic total and free cholesterol and TAG were determined according to Carr et al. (1993) following the extraction of hepatic lipids with chloroform-methanol $(2: 1)$. Cholesteryl ester concentrations were calculated by subtracting free from total cholesterol.

\section{Lipoprotein characterization}

VLDL and LDL composition were calculated by determining the relative percentage free and esterified cholesterol, protein, TAG and phospolipids in each lipoprotein. Protein was determined by a modified Lowry procedure (Markwell et al. 1978); total and free cholesterol by enzymatic methods (Allain et al. 1974), by enzymatic kits using a glycerol blank (Carr et al. 1993) and phospholipids by an enzymatic method. The number of constituent molecules of VLDL and LDL was calculated on the basis of one apo B per LDL particle with a molecular mass of $412000 \mathrm{kDa}$ (Chapman et al. 1975) and for VLDL by selective precipitation with isopropanol (Holmquit et al. 1987). The number of molecules of TAG, free cholesterol, esterified cholesterol and phospholipids were calculated using molecular weights 885.4, 386.6, 645 and 734 respectively (Fernandez et al. 1995). LDL diameter was calculated according to Van Heek \& Zilversmit (1991).

\section{Faecal neutral sterols measurement}

Faecal neutral sterols were measured by the method of Daggy et al. (1997). Dry faeces (250 mg) were saponified with of $0.3 \mathrm{M} \mathrm{KOH}(3 \mathrm{ml})$ and placed in a ReactiTherm heating block for $1 \mathrm{~h}$ at $70^{\circ} \mathrm{C}$. 5 - $\alpha$-Cholestane $(25 \mu \mathrm{l})$ was added as an internal standard. After $1 \mathrm{~h}$ the samples were removed from the heating blocks, cooled at room temperature and poured into a Whatman Autovial Syringeless Filter Device. Petroleum ether $(20 \mathrm{ml})$ and of DI water $(2 \mathrm{ml})$ were added to the filtrate and samples were mixed. A portion of the sample $(14 \mathrm{ml})$ was transferred to another tube and mixed after the addition of another $10 \mathrm{ml}$ of petroleum ether. A portion of this extract $(8 \mathrm{ml})$ was taken, dried under nitrogen, resuspended in methylene chloride $(500 \mu \mathrm{l})$, transferred into a polypropylene-footed glass GC vial, and analysed by capillary GC in a HP-5 ultra 2 column, $50 \mathrm{~m}, 0.33$ film thickness, 0.32 ID 1:100 split mode. Cholesterol, coprostanol, sitosterol, SI and stigmasterol were quantified by the use of appropriate standards.

\section{Statistical analysis}

One-way ANOVA was used to determine the differences among control and SI groups. The Newman-Keuls method was used as a post-hoc test (INSTAT, San Diego, CA, USA). Data are presented as means and SD, and differences were considered significant at $P<0.05$.

\section{Results \\ Effect of sitostanol on plasma lipids}

There were no significant differences in body weights among guinea pigs fed the different diets, indicating that all animals consumed similar amounts of nutrients (data not shown). Guinea pigs fed increasing doses of SI exhibited a dose-dependent trend in plasma cholesterol lowering. With $0.75,1.5$ and $2.25 \mathrm{~g} / 100 \mathrm{~g}$ SI, plasma cholesterol was lowered by 43,49 , and $53 \%$ respectively $(P<0.0001)$ compared to the control which had no SI and the same amount of dietary cholesterol (0.25 g/100 g; Table 2). There were no significant differences in plasma total cholesterol between the SI groups and the $(-\mathrm{C})$ group indicating that sitostanol lowered plasma cholesterol to the same extent as that found in guinea pigs fed low cholesterol diets (Table 2).

VLDL-C was 37-52\% lower in the SI groups compared to the control. A dose-dependent response was observed in LDL-C lowering. Intake of increasing doses of sitostanol $(0.75,1.5$, and $2.25 \mathrm{~g} / 100 \mathrm{~g})$ resulted in 47,53 and $61 \%$ lower plasma cholesterol respectively $(P<0 \cdot 0001$; Table

Table 2. Plasma total cholesterol, VLDL, LDL and HDL cholesterol and TAG of guinea pigs fed control diets (positive and negative), and increasing doses of SI (Values are in $\mathrm{mmol} / \mathrm{l}$ and are means and SD for $n$ guinea pigs per treatment)

\begin{tabular}{|c|c|c|c|c|c|c|c|c|c|}
\hline & \multirow[b]{2}{*}{$n$} & \multicolumn{2}{|c|}{$\mathrm{TC}$} & \multicolumn{2}{|c|}{ VLDL } & \multicolumn{2}{|c|}{ LDL } & \multicolumn{2}{|c|}{ HDL } \\
\hline & & Mean & SD & Mean & SD & Mean & SD & Mean & SD \\
\hline (+) Control & 10 & $5 \cdot 41$ & $1.63^{\mathrm{a}}$ & 0.35 & $0 \cdot 10^{\mathrm{a}}$ & 4.68 & $1.60^{\mathrm{a}}$ & 0.36 & 0.10 \\
\hline (-)Control & 10 & $2 \cdot 76$ & $1 \cdot 27^{\mathrm{b}}$ & 0.31 & $0.22^{b}$ & 1.84 & $0.75^{\mathrm{b}}$ & 0.47 & 0.10 \\
\hline SI $0.75 \%$ & 10 & $3 \cdot 10$ & $1.09^{b}$ & 0.17 & $0.08^{b}$ & $2 \cdot 51$ & $1.08^{\mathrm{b}}$ & 0.41 & 0.05 \\
\hline SI $1.50 \%$ & 9 & $2 \cdot 77$ & $0.69^{b}$ & 0.22 & $0.09^{b}$ & 2.22 & $0.72^{\mathrm{b}}$ & 0.34 & 0.10 \\
\hline SI $2.25 \%$ & 10 & $2 \cdot 38$ & $0.49^{b}$ & 0.19 & $0.11^{b}$ & 1.84 & $0.46^{\mathrm{b}}$ & 0.36 & 0.10 \\
\hline
\end{tabular}

TC, total cholesterol.

Numbers in a column with different superscripts are significantly significant as determined by one-way ANOVA and Newman-Keuls as post-hoc test $(P<$ $0.01)$. 
Table 3. Number of cholesteryl ester, free cholesterol, triacylglycerol, phospholipids molecules in VLDL of guinea pigs fed control diets (positive and negative), and increasing doses of sitostanol (SI)

(Values are presented as means and SD for the indicated $n$ number of guinea pigs per dietary treatment)

\begin{tabular}{|c|c|c|c|c|c|c|c|c|c|c|c|}
\hline & \multirow[b]{2}{*}{$n$} & \multicolumn{2}{|c|}{ CE } & \multicolumn{2}{|c|}{ FC } & \multicolumn{2}{|c|}{ TAG } & \multicolumn{2}{|c|}{ PL } & \multicolumn{2}{|c|}{ Diameter } \\
\hline & & Mean & SD & Mean & SD & Mean & SD & Mean & SD & Mean & SD \\
\hline Control & 10 & 2105 & 521 & 1143 & $404^{\mathrm{ab}}$ & 3888 & $1038^{a}$ & 1299 & 110 & 420 & $49^{a}$ \\
\hline (-)Control & 10 & 557 & 809 & 1042 & $972^{\mathrm{ab}}$ & 10394 & $3187^{b}$ & 1840 & 594 & 730 & $225^{\mathrm{b}}$ \\
\hline SI $0.75 \%$ & 10 & 1167 & 945 & 1698 & $800^{\mathrm{b}}$ & 10221 & $2292^{b}$ & 1629 & 350 & 631 & $160^{\mathrm{b}}$ \\
\hline SI $1.50 \%$ & 9 & 2026 & 2171 & 1860 & $556^{\mathrm{b}}$ & 11642 & $4583^{b}$ & 1657 & 474 & 640 & $175^{\mathrm{b}}$ \\
\hline SI $2.25 \%$ & 10 & 1129 & 1065 & 697 & $465^{\mathrm{a}}$ & 13910 & $4617^{b}$ & 1755 & 572 & 699 & $104^{b}$ \\
\hline
\end{tabular}

CE, cholesterylester; FC, free cholesterol; PL, phospholipid; SI, sitostanol; TAG, triacylglycerol.

Numbers in a column with different superscripts are significantly significant as determined by one-way ANOVA and Newman-Keuls as post-hoc test $(P<0.01)$

2). Moreover the plasma cholesterol lowering at the highest dosage of SI $(2.25 \mathrm{~g} / 100 \mathrm{~g})$ resulted in the same levels of plasma cholesterol, as guinea pigs fed relatively low levels of dietary cholesterol $(0.04 \mathrm{~g} / 100 \mathrm{~g}$; $-\mathrm{C}$; Table 2$)$. HDL cholesterol levels were unaffected both by SI and dietary cholesterol (Table 2).

\section{Effect of sitostanol on lipoprotein composition and size}

The number of molecules of free cholesterol in VLDL were lower in guinea pigs fed the highest dose of SI compared to the lower doses (Table 3). Guinea pigs from the three SI groups and from the $(-\mathrm{C})$ control had higher number of TAG molecules compared to the control. With $0.75,1.5$, and $2.25 \mathrm{~g} / 100 \mathrm{~g}$ SI, the number of TAG molecules were 62, 67 and $73 \%$ higher respectively $(P<0 \cdot 001$; Table 3$)$. Cholesteryl ester and phospholipids were unaffected by SI and dietary cholesterol. VLDL diameter was 35-40 \% larger by SI compared to the control $(P<0.0005$; Table 3$)$. Guinea pigs fed from the $(-\mathrm{C})$ group also had a $43 \%$ larger VLDL diameter compared to controls $(P<0 \cdot 001)$ (Table 3).

LDL derived from the control animals had a higher percentage of cholesteryl ester $(P<0.01)$ than the other groups (Table 4). Increasing doses of SI resulted in a decrease in the number of cholesteryl ester molecules by 40-46\% compared to controls. Moreover, SI intake resulted in number of cholesteryl ester molecules, comparable to guinea pigs fed the low cholesterol diet $(-\mathrm{C}$; Table 4). SI consumption lowered the number of free cholesterol molecules by $40-50 \%$ and guinea pigs from the $(-\mathrm{C})$ had

Table 4. Number of cholesteryl ester, free cholesterol, triacylglycerol, and phospholipid molecules in LDL of guinea pigs fed control diets (positive and negative), and increasing doses of sitostanol

(Values are means and SD for $n$ guinea pigs per dietary treatment)

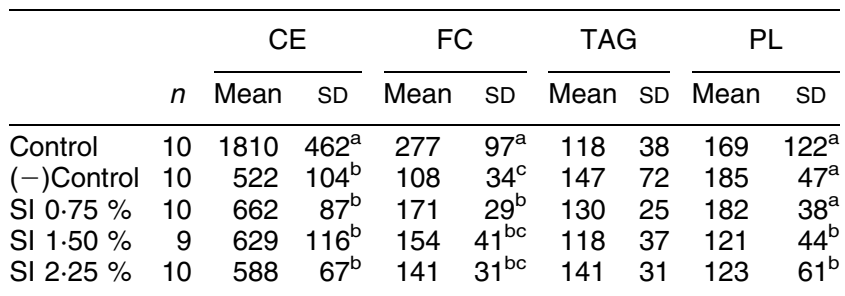

CE, cholesterylester; FC, free cholesterol; SI, sitostanol; TAG, triacylglycerol. Numbers in a column with different superscripts are significantly significant as determined by one-way ANOVA and Newman-Keuls as post-hoc test ( $P<$ $0.01)$ a $62 \%$ lower number of free cholesterol molecules than the control animals. LDL TAG were unaffected by SI or dietary cholesterol. With 0.75 and $1.5 \mathrm{~g} / 100 \mathrm{~g} \mathrm{SI}$, the number of phospholipid molecules were $28 \%$ lower compared to the control (Table 4).

\section{Effect of sitostanol on hepatic cholesterol pools}

SI intake resulted in 26-42\% lower hepatic total cholesterol compared to the control group $(P<0 \cdot 001)$. Due to the lower amounts of cholesterol in the diet, guinea pigs from the $(-\mathrm{C})$ control group had lower concentrations of hepatic total cholesterol compared to the other four dietary treatments (Table 5). Hepatic free cholesterol followed a similar trend to total cholesterol. Guinea pigs in the control group had higher hepatic free and esterified cholesterol than those animals in the sitostanol or the low cholesterol groups $(-\mathrm{C})$. Guinea pigs in the $(-\mathrm{C})$ group had the lowest amount of free cholesterol and SI consumption resulted in lowering of free cholesterol by 23-36\% and 32-60\% esterified cholesterol compared to controls $(P<0.001$; Table 5).

Hepatic TAG was also considerably lowered by SI. SI $(0.75 \mathrm{~g} / 100 \mathrm{~g})$ resulted in $55 \%$ decrease while 1.5 and $2.25 \mathrm{~g} / 100 \mathrm{~g}$ SI intake resulted in $61 \%$ decrease in hepatic TAG compared to the control (Table 5). Guinea pigs in the $(\mathrm{C}+)$ group had $87 \%$ lower hepatic TAG than the negative control. In all cases SI treatment resulted in a hepatic lipid profile similar to guinea pigs fed low levels of dietary cholesterol (Table 5).

\section{Effect of sitostanol on total faecal neutral sterols}

There was a significant increase in total neutral sterols by SI intake. At the highest doses of 1.5 and $2.25 \mathrm{~g} / 100 \mathrm{~g} \mathrm{SI}$, the amount of total neutral sterols was more than double the control and five times greater than the $(-\mathrm{C})$ group (Table 6 ). The higher amounts of total neutral sterols were mostly accounted for by increases in cholesterol and SI since faecal coprostanol concentrations were not different between SI treatment and control groups (Table 6).

Faecal SI was negligible in both the $(-\mathrm{C})$ and control groups and a dose-dependent increase in SI excretion was observed, consistent with the intake of increasing doses of SI (Table 6). 
Table 5. Hepatic total cholesterol, free cholesterol, esterified cholesterol, and triacylglycerol of guinea pigs fed control diets (positive and negative), and increasing doses of sitostanol in $\mu \mathrm{mol} / \mathrm{g}$

(Values are means and SD for $n$ guinea pigs per dietary treatment)

\begin{tabular}{lrllllllrr}
\hline & $n$ & \multicolumn{3}{c}{ TC } & & FC & & CE & TG \\
\hline Control & 10 & 6.20 & $1.70^{\mathrm{a}}$ & 4.50 & $1.21^{\mathrm{a}}$ & 1.69 & $0.79^{\mathrm{a}}$ & 21.57 & $6.32^{\mathrm{a}}$ \\
(-) Control & 10 & 1.75 & $0.59^{\mathrm{c}}$ & 1.57 & $0.54^{\mathrm{c}}$ & 0.23 & $0.18^{\mathrm{c}}$ & 4.17 & $1.47^{\mathrm{b}}$ \\
SI $0.75 \%$ & 10 & 3.78 & $2.18^{\mathrm{b}}$ & 2.88 & $2.21^{\mathrm{b}}$ & 0.90 & $0.51^{\mathrm{b}}$ & 9.71 & $6.44^{\mathrm{b}}$ \\
SI $1.50 \%$ & 9 & 4.63 & $2.29^{\mathrm{b}}$ & 3.47 & $1.88^{\mathrm{b}}$ & 1.15 & $0.51^{\mathrm{b}}$ & 8.69 & $5.08^{\mathrm{b}}$ \\
SI $2.25 \%$ & 10 & 3.65 & $0.85^{\mathrm{b}}$ & 2.95 & $0.77^{\mathrm{b}}$ & 0.69 & $0.48^{\mathrm{b}}$ & 8.47 & $5.31^{\mathrm{b}}$ \\
\hline
\end{tabular}

EC, esterified cholesterol; FC, free cholesterol; SI, sitostanol; TAG, triacylglycerol; TC, total cholesterol.

Numbers in a column with different superscripts are significantly significant as determined by one-way ANOVA and Newman-Keuls as post-hoc test $(P<0.01)$.

\section{Discussion}

Studies have shown that SI decreases plasma cholesterol in humans (Lees et al. 1977; Becker et al. 1993; Pelletier et al. 1995) and some animal models (Sugano et al. 1976, 1977; Ntanios \& Jones, 1999). However, specific effects of sitostanol on hepatic cholesterol and lipoprotein metabolism have not been fully elucidated. Guinea pigs are good models to study cholesterol and lipoprotein metabolism because of their similarity to the human situation, especially the fact that they transport the majority of cholesterol in the LDL fraction (Lin et al. 1994). It was therefore of interest to assess how SI influences lipoprotein metabolism in guinea pigs and to evaluate modifications in the intravascular processing of lipoproteins by measuring VLDL and LDL composition and size.

\section{Sitostanol effects on faecal neutral sterols}

In the present studies we found increased total neutral sterols in guinea pigs fed the SI diets, which suggests that the main mechanism of action of SI is decreasing cholesterol absorption. In agreement with our data, studies have suggested that SI is totally unabsorbable and decreases cholesterol absorption (Sugano et al. 1976, 1977). Our results are also consistent with other studies, where hamsters fed $1 \%$ SI showed a decrease in cholesterol concentrations due to a decrease in cholesterol absorption and an increase in faecal cholesterol excretion rate (Ntanios \& Jones, 1999). Subsequent to lowering cholesterol absorption and its excretion in the faeces, an upregulation of the fractional cholesterol synthetic rate was also observed in hamsters (Ntanios \& Jones, 1999).
SI, administered in the form of esterified or nonesterified margarines, has been shown to lower plasma total cholesterol in mildly hypercholesterolaemic subjects (Miettinen et al. 1995). Rapeseed oil margarines, containing phytosterols have been shown to inhibit cholesterol absorption (Vuorio et al. 2000). Plant stanol ester feeding in addition to lowering serum cholesterol has also been shown to increase the sterols that reflect cholesterol synthesis and decrease the non-cholesterol sterols that reflect cholesterol absorption (Gylling et al. 1999). Stanol ester margarines have been shown to lower serum total, LDL and VLDL cholesterol in humans by decreasing the cholesterol absorption efficiency by $68 \%$ (Gylling \& Miettinen, 1996). In addition, consistent with our data, the faecal neutral sterol excretion was increased with the stanol ester margarine consumption (Gylling \& Miettinen, 1996).

There have been several speculations on how SI may affect cholesterol absorption. One theory is related to the structure of the molecules. SI resembles cholesterol and differs just by having an ethyl group at position 24 and a saturated $\beta$-ring, which makes the molecule bulkier. This may lead to alterations in the bond angles and affect binding to enzymes and transport proteins (Ntanios \& Jones, 1999).

Phytosterol-cholesterol absorption may be influenced by the total sterol concentration in the oil, in the micellar, as well as solid phase (Mattson et al. 1977). As a metabolic consequence of lipolysis, free sterol could accumulate in the lumen of the intestine and selectively increase the precipitation of sterols (Ntanios \& Jones, 1999). SI, which is more hydrophobic than cholesterol, and has lower solubility than cholesterol, however, has a high affinity towards bile salt micelles (Wilson \& Rudel, 1994). Thus, SI

Table 6. Faecal neutral sterols and total neutral sterol concentration of guinea pigs fed control diets (positive and negative) and increasing doses of sitostanol in $\mathrm{mg} / \mathrm{kg}$ per $\mathrm{d}$

(Values are means and SD for $n$ guinea pigs per dietary treatment)

\begin{tabular}{|c|c|c|c|c|c|c|c|c|c|c|c|}
\hline & \multirow[b]{2}{*}{$n$} & \multicolumn{2}{|c|}{ Cholesterol } & \multicolumn{2}{|c|}{ Sitostanol } & \multicolumn{2}{|c|}{ Coprostanol } & \multicolumn{2}{|c|}{ Sitosterol } & \multicolumn{2}{|c|}{ TNS } \\
\hline & & Mean & SD & Mean & SD & Mean & SD & Mean & SD & Mean & SD \\
\hline $\begin{array}{l}\text { Control } \\
(-) \text { Control } \\
\text { SI } 0.75 \% \\
\text { SI } 1.50 \% \\
\text { SI } 2.25 \%\end{array}$ & $\begin{array}{l}5 \\
6 \\
6 \\
5 \\
6\end{array}$ & \begin{tabular}{r|}
$4 \cdot 6$ \\
$2 \cdot 6$ \\
$6 \cdot 9$ \\
$15 \cdot 3$ \\
$14 \cdot 4$
\end{tabular} & $\begin{array}{l}2 \cdot 6^{\mathrm{a}} \\
2 \cdot 72^{\mathrm{a}} \\
2.57^{\mathrm{a}} \\
3.46^{\mathrm{b}} \\
5.99^{\mathrm{b}}\end{array}$ & $\begin{array}{c}0 \\
0 \\
38 \cdot 6^{\mathrm{b}} \\
121 \cdot 8 \\
159\end{array}$ & $\begin{array}{l}0^{\mathrm{a}} \\
0^{\mathrm{a}} \\
15 \cdot 4^{\mathrm{b}} \\
30 \cdot 5^{\mathrm{c}} \\
54 \cdot 3^{\mathrm{d}}\end{array}$ & $\begin{array}{l}5 \cdot 14 \\
2 \cdot 16 \\
5 \cdot 18 \\
7 \cdot 08 \\
6 \cdot 36\end{array}$ & $\begin{array}{l}2 \cdot 7^{\mathrm{a}} \\
1 \cdot 79^{\mathrm{a}} \\
2 \cdot 39^{\mathrm{a}} \\
2 \cdot 55^{\mathrm{b}} \\
2 \cdot 25^{\mathrm{a}}\end{array}$ & $\begin{array}{l}3.53 \\
2.94 \\
2.99 \\
7.60 \\
8.40\end{array}$ & $\begin{array}{l}2.45^{\mathrm{a}} \\
1.92^{\mathrm{a}} \\
1.24^{\mathrm{ab}} \\
1.83^{\mathrm{b}} \\
3.56^{\mathrm{b}}\end{array}$ & $\begin{array}{r}13 \cdot 23 \\
6 \cdot 34 \\
15 \cdot 10 \\
31.01 \\
31.45\end{array}$ & $\begin{array}{r}7 \cdot 35^{\mathrm{a}} \\
4.22^{\mathrm{a}} \\
5.69^{\mathrm{ab}} \\
8.03^{\mathrm{b}} \\
12.52^{\mathrm{b}}\end{array}$ \\
\hline
\end{tabular}

SI, sitostanol; TNS, total neutral sterols.

Numbers in a column with different superscripts are significantly significant as determined by one-way ANOVA and Newman-Keuls as post-hoc test $(P<0.01)$ 
could replace cholesterol from the micellar mix and thereby render it less absorbable (Wilson \& Rudel, 1994; Heinemann et al. 1988, 1991, 1993).

There has also been speculation that the differences in the absorption of cholesterol and other plant sterols could also be due to differences in the rates of intracellular esterification within the enterocytes (Wilson \& Rudel, 1994). Studies have shown that free cholesterol is absorbed to a greater extent than the cholesteryl esters (Swell et al. 1955, 1960). All these studies are in agreement that plant sterols decrease cholesterol absorption by different means. Our present studies also found a decrease in cholesterol absorption as documented by the increased faecal neutral sterol concentrations in guinea pigs fed SI.

\section{Sitostanol effects on plasma and hepatic lipids}

High dietary cholesterol $(0.25 \mathrm{~g} / 100 \mathrm{~g})$ resulted in elevated plasma cholesterol in guinea pigs, consistent with other studies (Fernandez et al. 1992). In the present study, SI had a significant hypocholesterolaemic effect and a doseresponse trend was observed. A recent study by Hallikainen et al. (2000) in which individuals were fed 0.8, 1.6, 2.4 and $3.2 \mathrm{~g} / \mathrm{d}$ SI did not find a lowering of plasma LDL cholesterol with the lowest dose of SI. Similar to our data, the hypocholesterolaemic responses at the highest levels of 2.4 and $3.2 \mathrm{~g} / \mathrm{d}$ did not differ. Based on guinea pig average intake of food $(30 \mathrm{~g} / \mathrm{d})$, the doses in our study were equivalent to doses of $2.25,3.75$ and $7.5 \mathrm{~g} / \mathrm{d}$ in humans, higher than in the clinical study (Hallikainen et al. 2000).

SI intake not only affected plasma lipoprotein levels but also had a significant effect on lipoprotein composition. SI intake resulted in an increase in VLDL diameter, with a particle enriched in phospholipids and TAG. Larger VLDL enriched with TAG favour a slower conversion of VLDL to LDL (Nestel et al. 1983), which could possibly account for the lower plasma LDL cholesterol concentrations observed in guinea pigs fed the SI diets. In addition, the LDL generated from the SI diets was cholesteryl-ester-depleted and smaller in size. Smaller LDL particles, generated by dietary treatments such as polyunsaturated versus saturated fat intake have been shown to have a faster catabolism in guinea pigs (Fernandez et al. 1992, 1993). This could also be an explanation for the observed lowering of plasma LDL cholesterol with SI intake.

Higher concentration of hepatic cholesterol is associated with increased secretion of VLDL particles (Oshry et al. 1985). Moreover, when cholesterol is added to the diet the regulatory and ester pools of sterol in the liver are expanded and the activity of the LDL receptor is suppressed (Dietshy et al. 1993). Intake of SI resulted in lower hepatic free and cholesteryl ester concentrations, similar to guinea pigs fed low cholesterol diets $(0.04 \mathrm{~g} /$ $100 \mathrm{~g})$. This decrease in hepatic cholesterol could be associated with up-regulation of hepatic LDL receptors, which would accelerate the removal of LDL from plasma.

In addition, SI intake resulted in significant decreases in hepatic TAG similar to values found with low intake of cholesterol. Lower concentrations of hepatic TAG may be related to less secretion of VLDL (Ginsberg, 1990). It has been shown in rats that hepatic cholesterol increases hepatic TAG concentration due to a decreased synthesis of carnitine, a situation that promotes fatty acid synthesis rather than directing fatty acids towards $\beta$-oxidation (Fungwe et al. 1993). The lower concentrations of hepatic TAG in guinea pigs fed the SI diets was associated with a lower concentration of hepatic cholesterol in this study. These data suggest that the effects of SI in reducing the delivery of cholesterol to the liver not only affected hepatic cholesterol concentrations but also significantly reduced hepatic TAG. These reductions in TAG and cholesterol, the main components of VLDL, could be associated with decreased secretion of VLDL (Ginsberg, 1990) and contribute to the hypocholesterolaemic effects of SI.

\section{Conclusion}

We propose that part of the hypocholesterolaemic effect of SI might be related to decreased cholesterol absorption by the mechanisms explained above. This results in less delivery of cholesterol to the liver through the chylomicron remnant, which in turns affects hepatic cholesterol metabolism by decreasing the pools of hepatic cholesterol and TAG and possibly affecting the rate of secretion of VLDL. The secreted VLDL gets transformed into a larger mature VLDL, not readily converted to LDL. Compositional changes in LDL can also be related to enhanced catabolism and there might have been an up-regulation of LDL receptors in the liver from the SI-treated groups due to decreases in the regulatory pool of cholesteryl ester. The combination of these mechanisms contributes to the plasma LDL cholesterol lowering, observed by intake of SI.

\section{Acknowledgements}

This work is supported by the Monsanto Company.

\section{References}

Allain C, Poon L, Chan C, Richmond W \& Fu P (1974) Enzymatic determination of total serum cholesterol. Clinical Chemistry 20 , 470-475.

Becker M, Staab D \& Von-Bergmann K (1993) Treatment of severe familial hypercholesterolemia in childhood with sitosterol and sitostanol. Journal of Pediatrics 122, 292-296.

Carr T, Andressen CJ \& Rudel LL (1993) Enzymatic determination of triglyceride, free cholesterol and total cholesterol in tissue lipid extracts. Clinical Biochemistry 26, 39-42.

Chapman JM, Mills GL \& Ledford JH (1975) The distribution and partial characterization of the serum apolipoproteins in the guinea pig. Biochemistry Journal 149, 423-436.

Child P \& Kuksis A (1986) Investigation in the role of micellar phospholipid in the preferential uptake of cholesterol over sitosterol by dispersed rat jejunal villus cells. Biochemistry and Cell Biology 64, 847-853.

Daggy BP, O'Connell NC, Jerdack GR, Stinson GR \& Setchell KDR (1997) Additive hypocholesterolemic effect of psyllium and cholestyramine in the hamster: influence on fecal sterol and bile acid profiles. Journal of Lipid Research 38, 491502.

Dietshy JM, Turley SD \& Spady DK (1993) Role of liver in the maintenance of cholesterol and low density lipoprotein homeostasis in different animal species, including humans. Journal of Lipid Research 34, 1637-1657. 
Fernandez ML \& McNamara DJ (1994) Regulation of cholesterol and lipoprotein metabolism in the guinea pig mediated by dietary fat quality and quantity. Journal of Nutrition 121, 934943.

Fernandez ML, Lin ECK \& McNamara DJ (1992) Regulation of low density lipoprotein kinetics by dietary fat saturation. Journal of Lipid Research 33, 97-109.

Fernandez ML, Abdel-Fattah G \& McNamara DJ (1993) Dietary fat saturation modifies the metabolism of LDL subfractions in guinea pigs. Arteriosclerosis and Thrombosis 13, 1418-1428.

Fernandez ML, Sun DM, Montano C \& McNamara DJ (1995) Carbohydrate-fat exchange and regulation of hepatic cholesterol and plasma lipoprotein metabolism in the guinea pig. Metabolism 44, 855-864.

Fernandez ML, Wilson TA, Conde K, Vegara-Jimnez M \& Nicolosi RJ (1999) Hamsters and guinea pigs differ in the plasma lipoprotein cholesterol when fed diets varying in animal protein, soluble fiber or cholesterol content. Journal of Nutrition 129, 1323-1332.

Fungwe TV, Cagan LM, Cook GA, Wolcox HG \& Heimberg M (1993) Dietary cholesterol stimulates hepatic bio-synthesis of triglyceride and reduces oxidation of fatty acids in the rat. Journal of Lipid Research 34, 933-941.

Ginsberg HN (1990) Lipoprotein physiology and its relationships to atherogenesis. Endocrinology and Metabolism Clinics of North America 19, 211-222.

Gylling H \& Miettinen TA (1996) Effects of inhibiting cholesterol absorption and synthesis on cholesterol and lipoprotein metabolism in hypercholesterolemic non-insulin dependent diabetic men. Journal of Lipid Research 837, 1776-1785.

Gylling H, Puska P, Vartiainen E \& Miettinen TA (1999) Serum sterols during stanol ester feeding in a mildly hypercholesterolemic population. Journal of Lipid Research 40, 593-600.

Hallikainen MA, Sarkkinen ES \& Uusitupa MI (2000) Plant stanol esters affect serum cholesterol concentrations of hypercholesterolemic men and women in a dose-dependent manner. Journal of Nutrition 130, 4767-776.

Heinemann T, Pietruck B, Kullak-Ublick G \& Von-Bergmann K (1988) Comparison of sitosterol and sitostanol inhibition of intestinal cholesterol absorption. Agents and Actions 26, S117S122.

Heinemann T, Pietruck B, Kullak-Ublick G \& Von-Bergmann K (1991) Mechanisms of action of plant sterols on inhibition of cholesterol absorption. Comparison of sitosterol and sitostanol. European Journal of Clinical Pharmacology 40, S59-S63.

Heinemann T, Axtmann G \& Von-Bergmann K (1993) Comparison of intestinal absorption of cholesterol with different plant sterols in man. European Journal of Clinical Investigation $\mathbf{2 3}$, 827-831.

Holmquit L, Carlson K \& Carlson AL (1987) Comparisons between the use of isopropanol and tetramethyl urea for the solubilization and quantitation of human serum very lowdensity lipoproteins. Analytical Biochemistry 88, 457-460.

Ikeda I \& Sugango M (1983) Some aspects of mechanism of inhibition of cholesterol absorption by beta-sitosterol. Biochimica et Biophysica Acta 732, 651-658.

Lees AM, Mok HY, Lees RS, McCluskey MA \& Grundy SM (1977) Plant sterols as cholesterol lowering agents: clinical trials in patients with hypercholesterolemia and studies of sterol balance. Atherosclerosis 28, 325-338.

Lin ECK, Fernandez ML \& McNamara DJ (1994) Dietary fat type and cholesterol quantity interact to affect cholesterol metabolism in guinea pigs. Journal of Nutrition 122, 2019-2029.

Markwell MAS, Haas SM, Bieber LL \& Tolbert NE (1978) A modification of the Lowry procedure to simplify protein determination in membrane and lipoprotein samples. Annals of Biochemistry 87, 206-210.
Mattson FH, Volpenhein RA \& Erickson BA (1977) Effect of plant sterol esters on the absorption of dietary cholesterol. Journal of Nutrition 107, 1139-1146.

McNamara DJ (1992) Dietary fatty acids, lipoproteins and cardiovascular disease. Advances in Food and Nutrition Research 36, 251-253.

Miettinen TA, Puska P, Gylling H, Vanhanen H \& Vartiainen E (1995) Reduction of serum cholesterol with sitostanol-ester margarine in a mildly hypercholesterolemic population. New England Journal of Medicine 333, 1308-1312.

Nestel P, Billington N, Tada P, Nugent P \& Fidge N (1983) Heterogenity of very-low-density lipoprotein metabolism in hyperlipidemic subjects. Metabolism 32, 810-817.

Ntanios FY \& Jones PJ (1998) Effects of variable dietary sitostanol concentrations on plasma lipid [profile and phytosterol metabolism in hamsters]. Biochimica et Biophysica Acta 1390, 237-244.

Ntanios FY \& Jones PJ (1999) Dietary sitostanol reciprocally influences cholesterol absorption in hamsters and rabbits. Atherosclerosis 143, 341-351.

Ntanios FY, MacDougall DE \& Jones PJ (1998) Gender effects of tall oil versus soybean phytosterols as cholesterol lowering agents in hamsters. Candian Journal of Physiology and Pharmacology 76, 780-787.

Oshry R, Olivecrona T, Deckelbaum RJ \& Eisenberg S (1985) Is hypertriglyceridemic very low density lipoprotein a precursor of normal low density lipoprotein? Journal of Lipid Research 26, 158-167.

Pelletier X, Belbraouet S, Mirabel D, Mordret F, Perrin JL, Pages X \& Debry G (1995) A diet moderately enriched in phytosterols lowers plasma cholesterol concentrations in normocholesterolemic men. Annals of Nutrition and Metabolism 39, 291-295.

Redgrave T, Roberks C \& West C (1975) Separation of plasma lipoproteins by density gradient ultracentrifugation. Annals of Biochemistry 65, 42-49.

Rong N, Ausman LM \& Nicolosi RJ (1997) Oryzanol decreases cholesterol absorption and aortic fatty streak in hamsters. Lipids 32, 303-309.

Salen G, Ahrens EH Jr \& Grundy SM (1970) Metabolism of betasitosterol in man. Journal of Clinical Investigation 49, 952967.

Stamler J, Wentforth D \& Neaton JD (1986) Is relationship between serum cholesterol and risk of premature death from coronary heart disease continuous and graded? Findings in 356222 primary screens of the multiple risk factor intervention trial (MR-FIT). JAMA 256, 2823-2828.

Sugano M, Kamo F \& Ikeda I (1976) Lipid lowering effect of phytostanols in rats. Atherosclerosis 24, 301-309.

Sugano M, Morioka H \& Ikeda I (1977) A comparison of hypocholesterolemic activity of beta sitosterol and betasitostanol in rats. Journal of Nutrition 107, 2011-2019.

Swell L, Field H Jr \& Treadwell CR (1960) Absorption of cholesterol-4-C ${ }^{14}$ oleate. Proceedings for the Society of Experimental Biology and Medicine 103, 263-266.

Swell L, Boiter TA, Field H Jr \& Treadwell CR (1955) Absorption of dietary cholesterol esters. American Journal of Physiology. 180, 129-132.

Warnick GR, Bederson J \& Albers JJ (1992) Dextran-sulfate$\mathrm{Mg}^{+2}$ precipitation procedure for quantitation of high density lipoprotein cholesterol. Clinical Chemistry 28, 1397-1388.

Weihrauch JL \& Gardner JM (1978) Sterol content of foods of plant origin. Journal of American Dietetics Association 73, 3947.

Weststrate JA \& Meijer GW (1998) Plant sterol-enriched margarines and reduction of plasma total- and LDL-cholesterol 
concentrations in normocholesterolaemic and mildly hypercholesterolaemic subjects. European Journal of Clinical Nutrition 52, 334-343.

Wilson MD \& Rudel LL (1994) Review of cholesterol absorption with emphasis on dietary and biliary cholesterol. Journal of Lipid Research 35, 943-953.

VanHeek M \& Zilversmit D (1991) Mechanisms of hypertriglyceridemia in the coconut oil/cholesterol-fed rabbit. Increased secretion and decreased catabolism of VLDL. Arteriosclerosis and Thrombosis. 11, 918-927.

Vuorio AF, Gylling H, Turtola H, Kontula K, Ketonen P \& Miettinen TA (2000) Stanol ester margarine alone and with Simvastatin lowers serum cholesterol in families with familial hypercholesterolemia caused by the FH-north karelia mutation. Arteriosclerosis, Thrombosis and Vascular Biology 20, 500-506. 